\title{
Çocuk ve Ergenlerin Intihar Davranışına Yönelik Bütünleyici Bir Tedavi Yaklaşımı *
}

\author{
Çeviren R .Uslu
}

Ozet :Çocuk ve ergen intihariarı son yllarda giderek artmaktadr.Çocuk ve ergenlerde intihar girişimi ve tamamlan mamıs intharler ile ilgili yüksek risk etkenleri tartışılmıs ailelerin tepkileri ve terapi sürecinde bu tepkiterin geçirdiği aşamalar verilmiştir.

Saat 02.00 'de J'nin telefonu jle uyandım. Paniğe kapılmış gibiydi : "Bu sefil yaşamı sona erdirmek üzereyim. Elimde bir avuç dolusu hap var. Siyanür bile var" dedi. 17 yaşında, davranım bozukluğu, madde ve alkol sorunlari olan cok saldırgan bir gençti. Anababasının evinden atılmıştı. $O$ gece, uyuşturucu madde satışı nedeni ile tutuklanmıştı. Telefonda, onu hastaneye yatırmazsam kendini "gerçekten" öldüreceğini sōyledi. İaçiari yutmadan önce, size telefon ederek yardım istediğimi ancak sizin bunu reddettiğinizi belirten bir intihar mektubu bırakacağım. Bir gazeteye telefon ederek bu mektubu onlara okuyacağım. Bana yardım etmelisiniz" dedi. Uzun bir telefon konuşmasından sonra onu, ileri değerlendirme için acil servise başvurmaya ikna edebildim. Hastaneye değil ama, daha ōnce tedavi görmüş olduğu bir eve kabul edildi. Şimdi hayatta, ancak suça yŏnelik davranışları nedeniyle başı hala dertte.

Intihar eğlimi olan çocuk ve ergenlerle çalışmak güç olduğu kadar ódüllendirici, klinik deneyim kazandırıcidır. Çocukların ve gençlerin kendine zarar verici davranışları, ailelerini, arkadaşlarını, sağlık ve ruh sağlığı çalışanlarını cok etkilemektedir.

Intihar, pek çok ülkede gençlerin ölüm nedenleri arasında ilk öç sirada yer almaktadır. Tüm yaş gruplarında yıllık intihar oranları Yunanistan'da 100.000/2.9. Macaristan'da
100.000/44.9, ortalama 10.0'dur Kanada, 1983 de 15. 1/100.000 oran ile Dünya Sağlık Orgütü'nün (WHO) listesindeki ülkeler içinde ilk sıradayer almakta idi. Dahası, Kanada'nın bugünkü oranı ABD'de aşmıştır. Ingilltere'de 1980'de genel intihar oranı $9 / 100.000$ idi. Birleşik Devletler'in intihar orani 1968-1983 yilları arasında 10-14/100.000 idi. Kuzey Amerika ve diğer batilı ülkelerde 1981 ylinda, 10-19 yaşındaki (ergenlik dönemindeki) ve 20-29 yaşındaki (genç erişkinjik dönemindeki) erkekler yüksek risk gruplari olarak belirfenmişierdir. 1981'de $15-19$ yaş grubu erkeklerin intihar oranı $13.8 / 100.000$, aynı yaş grubu kizlarin ise $3.6 / 100.000$ idi. 1980'de ingiltere ve Galler'de aynı yaş grubundaki erkeklerin intthar oranı erkeklerde 21.2 , kızlarda 3.8 olarak saptanmıştır.

Kanada'da genclerde intihar oranı son 30 yılda üç kat artmış olmasına karşın, diğer yaş gruplarinda hafif artma ve azalmalar gözlenmektedir. Intihar tehditleri ve girişimleri de çocuk ve ergen psikiyatrik hastalarda en sık rastianan soruniardandir. Son yaymlarda Amerika Birleşik Devletlerinde 5-14 yaş grubunda yilda 12.000 çocuğun intihara yönelik davraniş nedeni ile psikiyatri hastanelerine başvurdukları bildirilmektedir.

Koruyucu psikiyatri alanındaki çalışmaları geliştirmek için intihar davranışını daha iyi anlayabilmek gerekir. Bu amaçla tüm sağlık ve ruh

\footnotetext{
*Turgay, A. An Integrative approach to child and adolescent suicidal behavior, Psychiatric Clinics of North America 12, 4, , 971-985, 1989
} 
sağıı̆ı calışanları tarafından önemli adımlar atımıştır. İtiharla ilgili olarak henüz pek çok yanıttanmamıs soru ve celişkili varsayım vardır. Cevresel etkenterin, rutsal hastalığın rolünün, hazırlayıcı genetik veya biyokimyasal etkenterin ve tüm biyolojik, psikolojik ve sosyal etkenlerin etkileşimlerinin daha lleri düzeylerde araştırımaları gerekmektedir. Intiharın, daha önce sanıldığı gibi tümúyle ayrı bir grup oluşturmadıkları konusunda bir ölçude fikir birliğine varı̀mıştır.

Cocuk ve ergen intiharlart konusundaki literatür gózden geçirildiğinde bu alandaki eğilimleri, aşırı vurgulanan ve gözardı edilen konuları görmek mümkündür. Çalışmaların çŏu, klinik orneklemlerde kendine zarar verici davranışlar veya intihar gırişimierine odaklanmaktadır. Tamamlanmış intiharları ele alan calışma sayısı azdır. Tamamianmış intihar konusundaki bilgimizi sorunun ciddiyeti $\mathrm{fle}$ karşılaş̧ırdığımızda, biyolojik etkenler, tedavi, korunma ve izleme gibi konulardaki boşluklarmn doldurulması gerektiğini anlıyoruz. Literatürde görülen ortak eğilim, kolay elde edilen epidemiyolojik verilerin ve sorunun ciddiyetine iliş̧in düşūncelerin fazlasıyla vurgulanması yönündedir. Araştırmalar en çok, yüksek risk etkenlerine odaklanmıştır. Son zamanlarda yapıimış olan ve kliniğe başvurmamış ömeklem gruplarını ele alan çalışmaların ónemi büyưktūr. Pfeffer ve arkadaşları, çocuklarda intihar davranışına ilişkin birçok değişkenin ortaya konmuş olmasına karşın bu etkenlerın anlamlı̈ı̆̆nı gösteren pek az sağlam kanıt olduğunu belirtmişlerdir. Literatürde yaklaşım, tedavi ve korunma konularında onemli bır boşluk vardır. Pfeffer, intihar eğilimi olan hastaiarda psikoterapinın etkinliğini değerlendiren sistematik çalışma olmadığını bildirmiştir. İntihar eğilimi olan çocuklara uygulanan psikoteraplye iliş̧in bilginin "ampirik olarak araştırılan kuramsal içgörü" üreten olgu bildirimlerinden elde edildiğini belirtmiştir. Bu yazıda kendine zarar verici davranışın epidemiyolojik bzellikleri, cocukluk ve ergentikte intihar girişimi ve tamamlanmamış intihar ile ilgijı yūksek risk etkenlerf gözden geçirilmiştir. Bu nedenle, bu yazının odağı olarak, çocuk ve ergenlerin intihar davranışına karşı ailelerin tepkileri ve terapl boyunca bu tepkilerin geçirdiğı aşamalara sürecinde vermeye yöneliktir.

\section{YÖNTEM :}

Bu yazida anahatian lite sunulan klinik bulgular ve terapötik yaklaşımlar, yazarın son 15 yilda Hacettepe, Ottawa ve Mc Master Üniversiteleri çocuk klinikleri ve cocuk hastanelerindekl çalısmaları sırasında oluşmaya başlamıştır. Son 6 yılda intihar eğilimi ofan çocuk ve ergenler ile yaptı̆̆ı çalışmalar ise ilk formūlasyonların doğrulanması veya değiştiriłmesi olanağını vermiştir. Grup tartışmaları, servis vizitleri asistan süpervizyonları, tek yönlü aynadan yapilan gözlemler, bireysel görüşme ve aile görüşmelerinin video kayıtları, úst dúzey nesnelliğe ulaşmasını sağlamıştır.

Yazar Mayıs 1981 ve Nisan 1988 tarihleri arasında 139 cocuk ve ergeni, aileleri ile birlikte, çocuk ve aile tedavisinde bütünleyici yaklaşımın kullanarak degerlendirmiş ve tedavi etmiştir. Bu çocuk ve ergenlerin yaş, cins dağılımları ve DSM III Eksen I taniları Tablol ve ll' de görütmektedir.

Tablo I : Yaq Dabinm

\begin{tabular}{|l|l|c|c|}
\hline Yas & Erkek & $K ı z$ & Topiam \\
\hline 9 yas ve altı & 2 & - & 2 \\
10 yaş & 1 & 1 & 2 \\
11 yaş & 2 & 1 & 3 \\
12 yaş & 3 & 5 & 8 \\
13 yaş & 4 & 9 & 13 \\
14 yaş & 6 & 24 & 30 \\
15 yaş & 9 & 32 & 41 \\
16 yaş & 8 & 14 & 22 \\
17 yas ve ustu & 8 & 10 & 18 \\
\hline TOPLAM & 43 & 96 & 139 \\
\hline
\end{tabular}

Tablo II : Intihar Girlogimi olan 139 Cocuk ve Ergenin DSM If Eksen I Tani Daculimi

\begin{tabular}{|l|c|c|c|}
\hline Tanı & Erkek & $\mathrm{K} I \mathrm{Z}$ & Toplam \\
\hline Uyum boz & 14 & 45 & 59 \\
Davranım boz & 13 & 22 & 35 \\
Depresyon & 10 & 17 & 27 \\
Sinır kıs Boz & 1 & 8 & 9 \\
Anoreksıya ne & - & 2 & 2 \\
Madde Bag & 2 & - & 2 \\
ADHD & 1 & - & 1 \\
Ozdeşım sor & 1 & - & 1 \\
Madde alımına & & & 1 \\
bağlı psıkoz & 1 & - & 1 \\
Kaygi Boz & - & 1 & 1 \\
SizofBoz: & - & 1 & 139 \\
\hline TOPLAM & 45 & 95 & \\
\hline
\end{tabular}

59 olgu uyum bozukluğu tanısı almış olup bunjarın 53'ünūn çőkkün duygu durumlu olduğu górülmektedir. 90 çocuk başlangıçta ortalama 4 hafta 
süre lie yatarak tedavi görmüştür. Bu hastaların cogu (önceden başka terapistler tarafından izlemeye alınmışiardı. Hastanede yattıkları süre boyunca bu hastalar yoğun biçimde değerlendirmeye alınmış ve terapi uygulanmıştır. Bu ayrıntılı değerlendirmeler hastaların patolojllerine, aile ve tedavi ekibinin tepkisine itişkin pek cok veri sağlamıştır. 49 hasta, Doğu Ontorio Çocuk hastanesi'nin acil servisinden random örneklem yơntemi ile seçilmiştir. Asistanlar ve todavi ekibinin diğer ìyeleri tarafından yatırıtan 90 hasta ise daha sonra yazara sevk edilmişlerdir. Olguların çŏ̌unda süresi 1.5-2 saat olmak üzere, en az 20 seans ve aileler tie on az 15 seans görüşme yapılmıştır. Bulgu ve sonuçar, bu derinlemesine klinik çalışmalardan elde edilmiştir. Olguların çoğunda, bir psikiyatri asistanınında katılımı vardır.

Bu yazıda, yer darlığı nedeni ite farmakoterapi, bireysel terapi, aile desteği ile yürüyen grup ve ortam tedavileri üzerinde durulmayacaktır. Literatürde allenin korunma, değerlendirme ve tedavideki rolü önemli ölçüde gözardı edilmiş olduğundan bu yazıda tanı ve tedavi bağlamında ailenin intihar davranışına tepkisi uzzerinde durulacaktır. Yazarın söz konusu 139 çocuk ve ergen ile yaptığı çalışmaların diğer bulguları başka yazılarda aktarılacaktır.

Bu çalışmada, çocuk ve ergenlerin intihar davranışına yönelik olarak uygulanan, tanı koyma, terap̣i ve korunma ögelerini içeren yaklaşıma "bütōnleyici yaklaşım" adı verilebilir.

\section{BÜTÜNLEYICI YAKLAŞM}

Yazarın bütünleyici yaklaşım ile çocuk ve ergenlerin kendine zarar verici davranışına illişkin kuramlar, araştırmalardan ve uygulamalardan elde edilenleri bir araya getirmeye çalışmaktadır. Amaç, intihar davranışını önlemek ve denetlemektir. Bunun için sistematik, kapsamlı, yoğun ve bütūnleşmiş bir tanı ve tedavi yaklaşımı oluşturmaya çalışilmıştır.

Oncelikle, kuramsal dozeyde bütünleme amaçlanır. Tanınmış kuramların ve tedavi yaklaşımlarının uygun yanlarınin bir araya getirilmesine çalışıır. Orneğin, biyolojik, psikodinamik, davranış̧i, bilişsel, stratejik, yaşantısal ve sistemik kuramlar kullanılı. Yaşamın sonlandırıması tehdidi ciddi bir konu olduğu ve intihara eğilimıl hastałarın özellikleri ve gereksinimleri çok farklt olduğu için, terapistin, hastaların coğuna uygulayamayacaği tek bir" terapi okulu modeline" sadik kalması güçtür. Intiharda krize müdahalenin, alie ve psikofarmakoterapinin tedaviye katılması gerekir.

İkinci olarak, müdahale için hedef sistem seçimi yapılır. Pfeffer'in de belirttiği gibi, pek çok olguda cocuk müdahalenin merkezi olarak alınmakla birlikte, zaman zaman tedavinin odağını değişik amaçar uğruna aileye, okula ve topluma kaydıracak ölçüde esnek olmalıdır. Dinamik, bütünleyici bir modelde "ilgi odağı" sürekli değişir. Terapist cocukla sürdūrdüğü bireysel terapiye bir süre için ara vererek, çocuğa günah keçisiymiş gibł davranan aileyi ele alabilir. İntihar eğilimi majör depresyon veya psikoz ile ilişkili ise, ilaç tedavisi merkez alınarak, cocuğun psikoterapisi, aile ve ortam yaklaşımları tamamlayıcı olarak kullanslabilir. Üçüncü bütünteme dözeyi, birincil, ikincil ve ügüncül korumayı ilgiliendirir. Çocuk ve ergen intihar davranışının, klinik psikiyatrik sendromlar ile ilişkili olduğu kesin olarak anlaşılmıştır. Intihar eğilimi olan cocuk ve ergenlerde en stk saptanan klinik sendromlar depresyon, davranım bozukluğu, uyum bozukluğu, psikoz, madde ve alkol kullanım bozukluklarıdır. Bu çocuk ve ergenlerin koruma, değerlendirme ve tedavileri, klinik sendromlarin genel tedavisinden ayıı tutulamaz. Koruma söz konusu olduğunda, klinik sendromlarin aflesel ve genetik yanları da gōzönüne alınmalıdır. Intiharı önleme söz konusu olduğunda, intihar davranışı lle yakından ilişkili olan bu klinik sendromların daha iyj tanınmaları ve tedavi edilmeleri gerekmektedir.

Çocuk veya ergenin kendine zarar verici davranışı ile, ailenin diğer bireylerinde saptanan ruhsal hastalık ve intihar davranışı arasında karşılıkıı bir ilişkl vardır. Bu ilişki, birincil koruma calışmalarında, ruhsal hastalığı olan bireylerin ailelerinin yüksek risk grubu olarak değerlendirilmelerini gerektirir. Bu ailelerden affektif hastalık, antisosyal davranışlar ve madde kötüye kullanımı ile yüklü olanłara yőnelmek en doğrusu olacaktır.

Ailede intihar etmiş bir birey varsa, o bireyin yalnız çocuklarında değil, diğer akrabalarında da intihar etme riskinin yüksek olduğu belirienmiştir. Yüksek risk taşıyan bu aileleri "intihar açısından birincil korunmanın" hedefi olarak seçmek gerekir. 
Ruhsal bozukluğun erken tanı ve tedavisi yolu ile, aynı aile için ikincil korunma da gerçekleştirilebilecektir. Depresyon veya davranım bozukluğu olan ancak, tanısı konmamış ve tedaviye alımmanış bir ergen yüksek intihar riski taşımaktadir. Kronik ruhsal hastalığın aile uzerindeki olumsuz etkisi o denil fazladır ki, ücüncül korumanın (rehabilitasyon) müdahaleye eklenmesi, birincil korumaya da büyük katkıda bulunacaktır.

Intihar davranışına boutünleyici yaklaşımda hedef sistemler, cocukl ergen, aile, okul, arkadaş cevresi, sağlık/ruh sağlığı sistemi ve toplumdur.

Kendine zarar verici davranışın tedavisinde psikofarmakoterapi giderek ónemli bir yer edinmektedir. Yine de, intihar eğitimi olan hastanın tedavisi yalnızca ilaç kullanımma indirgenemez. İlaç seçiminde "klinsik sendrom" gőzetilit. Omeğin, depresyonu olan hastaya antidepresan, psikotik hasta için antipsikotik, dikkat eksikliği-hiperaktivite gösteren hasta için psikostimülan ilaçlar secilir. Ayrıca hedef belirtilere yönelik ilaç kullantlabilir. Orneğin, davranım bozukjuğundaki saldırgan ve dürtüsel davranışlar hedef alinabilir.

Bütünleyici yaklaşımı benimsemiş terapist tedavinin odağını ayaktan (bireysel) tedaviden, yatarak(ortam) tedavi ve farmakoterapiye kaydrabilir. Çocuğun psikoterapisi, ailenin desteklenmesi ve aile tedavisi ile bütünlenmiştir.

\section{INTIHAR EĞLLIMI OLAN COCUK VE ERGENLERIN AILELERI}

"Ailemiz sürekli olarak J'nin intihar girişimierinin tehdidi altında. Artık yeter. Korkarım artık ałdırmaya başiayacağız" Bu sózleri, 15 yaşındaki bir hastanın annesi hastanın intihar girişiminden bir gün sonra yaptığım aile seansında söylemişti. 16 yaşında, kendine yönelik tekrarlayıcı zarar verici davranışı olan bir erkek çocuğun babası, aile seasında eşine dönerek "R. đünyanın merkezi oldu. Diğer çocuklar ne olacak? Ya bizim mesleklerimiz? "diye sordu. 11 yaşındaki M.annesine "Yapmak istediğim tek şey kendime, kız kardeşimin kendisine yaptığından daha etkili bir biçimde zarar verebilmek" dedi. Aynı seansta M.'nin, 16 yaşındaki ablasının çok miktarda ilaç alarak elde ettiği ikincil kazançiara "imrendiğj" anlaşıidı.
Alle bireylerinin ve bir sistem olarak allenin, cocuk ve ergenierin intihar davranışarma tepkileri basite indirgenemez. Literatüre bakıldığında intihar eğilimi olan hastaların alleleri lle ilgili bilgimizin ne denli kısıtlı olduğu görullưr.

Bazı yayınlarda, intihar davranışının etyolojisinde ailenin işlev bozukluğunun payına değinilmiştis. Bender ve Schilder, cocuğun intihar girişiminin ilgi toplama ozelliği taşıdığını farketmişlerdir. Schrut, karmaşalı ve gergin aile ortamını tanımlamış ve cocuğun intiharı girişimini, bu rahatsız edici ortamı değiştiremeyişinin bir belirtisi olarak kavramiaştirmıştir. Lawler ve ark., Mattson ve ark., çocuğun intihar davranış̧ının, alie ve çevreye yönelik bir yardım cağrısı olduğunu belirtmişierdir

Sabbath "harcanabilir cocuk" kavramin! tanımlamıs, cocuğun, ailenin kendisinden kurtulmaya odaklanmış düşmanca isteklerine "bilinçdışi yanit" verdiğini öne sürmöştur. Onlara göre ailenin gereksinim duymadığ ve dayanamadığı, anne ve babasının ruhsal bozukluğu bağlamında belirłi bir gereksinime hizmet eden ve aile yaptsında hassas dengenin korunmasını sağlayan klşidir.

Corder ve ark, intihar eğilimi olan cocukların ailelerinde sıcak yetişkin ózdeşim figurlerinin olmadığını kaydetmiştir. Pleffer, intihar eğilimi olan cocuklarin ailelerini niteleyen 5 önemli özellik saptamıştır. Kuşakar arası sınırlartn olmamast, ana baba itişkilerinde şiddetli çatışma olması, anababanın cocuğa yansittıkları duygular, sembiyotik anababa-çocuk, esnek olmayan bir aile sistemi.

Cocuk ve ergende intihar ve intihar girişimi üzerinde yapılan çalışmalarda int/har davranışı ile diğer aile ozzellikleri arasında sistematik bir etkileşim olduğu gösterilmiştir. Ailede ruhsal hastalik, ailede intihar öyküsü, aile içi uyuşmazlık, ayrilma ve boşanma lie cocuk ve ergenin kendine zarar verici davranışı arasında güçlo ilişikiler vardır. Cocuk ve ergenlerin intiharında ailenin rolü pek çok yazar ve araştımacı tarafından önemli bulunmuştur. Ne yazık ki, aile sisteminin, kendine zarar verici davranıştan korunma ve tedavi gibi konulardaki etkinliği pek bilinmemektedir.

Aile ile çafışırken, çocuk veya ergenin intihar davranışı uzerinde etkili olabilecek aile 
özellikderi ele alınır. Yazarın, çocuk ve ergenlerde intihar davranişınin değerlendirilmesi ve önlenmesinde, ailenin rola konusunda yaptığı kapsamlı bir çalışmada, son 6 yıl içinde 139 çocuk, ergen ve aileleri değerlendirmiştir.

Çalışmada en çok önem verilen konulardan biri, cocuk ve ergenin intihar davranışının aile üzerine olan etkisi idi. İntihar girişiminin ardından çocuk ve alle lle yapilan görūşmelerde, aileterde bazı ortak tepkiler, temalar ve örūntūier tanımland.

Tedavi sırasında ailelerin şu aşamalardan geçtikderi gơ̆rüloü:

\section{1. Şok ve korku}

2. Panik ve harekete geçme

3. Suçluluk

4. Óke

5. Onarma

6. Kısmi iyileşme

Bazı aileler ilk aşamalarda takılabilitier. Bu dönemier birbirinden kesin sınırlarta ayrılamazlar. Basite indirgenmemeleri gerekir. Farklı dönemlere iilşkin pek çok duygusal tepkiler ve savunmalar bir arada yaşanabilir. Son aşamaya ulaşmak aylar alabilir. Aile bireylerinin her biri bu aşamalardan farklı sürelerde geçebilir. Olguların çoğunda terapötik süreç sayesinde aile bireyleri birbirlerinin duygu ve tepkilerini daha iyi anlama olanağı bulurlar. Bu tepkiler, intihar eğilimi olan çocuğun kişilik yapısı ve ruhsal bozukluğuna llişkin özelliklerden etkilenirler.

Çocuğun intihar girişiminde bulunduğu oğrenildıği anda ailede "şok" yaşamaya başiar. Inanmazlık ve yadsıma eğilimleri görülür. "Olamaz!", " O olamaz!", "Nasil olur?", "Ciddi olamaz!" veya "Şimdi ne yapacağız?" gibi ifadeler sık kullanuır. İntihar girişiminde bulunan çocuğun yaşamını kurtarmak veya acil tıbbi girişime ulaştırmak gerekiyorsa, pek çok ailenin bu saş̧ıınııktan çabuk sıyrıldığı görülür. İntihar girişiminde bulunan kişiyi yitirme korkusu şok dönemine son vererek harekete geçine dönemini başlatır. Başkaları yardıma cağrıłır, hastaneye koşulur. Bu dỏnemde çok yoğun duygular yaşanır. Aile äyeleri intihar girişiminde bulunmuş bireyi hastane personeline teslim ettiklerinde ancak bu güçlū duyguların farkına varabilirier. "Panik", güçłó çatı̧̧ma ve duyguların yarattığı, durumun gerçeğine uygun yoğun kaygıdır. Buraya dek betmienmiş duygu ve tepkiler bir arada yaşanabilecekleri gibi, dönemier arasında ileri geri gidiş geliş olabilir.

Aile bireylerinln hem inthar girişimine, hem de terapistin destekleyici tedavi yaklaşımına tepkilerini belirleyen pek çok etmen vardır. Çocuğun ruhsal bozukluğu, aile işleverinin sağlıki ve sağlıksız yanları, önerilen tedavinin özellikleri, ailenin krizle başetme becerileri cocuğun kişilik yapısı ve girişimin ciddiyeti gibi. Bu değişkenier nası olursa olsun, ailede başlangıçta belirli bir düzeyde şok, inanmazlık ve yadsıma gibi tepkiler görülür.

Aile bireyleri acı ve kırgınlık duyariar. Kendilerini alçaltılmış hissederler. Intihar girişiminde bulunan bireyin sonunlarını "açacak" kadar onlara gũvenmediğini düşünürler. Çocukiarın yitirme korkusu, hayal kırıklığı, öfke ve hatta nefret gibi duyguların yüzeye çımasını engeller. Bu olumsuz duygulardan suçłuluk duyguları da filizlenebilir. Intihar girişiminde bulunan bireyi cezalandırma, vermeleri beklenen sevgi ve bakımı esirgemekle tehdit ederek ondan intikam alma eğilimleri de sık görôtür. Çocuk, doğrudan veya dolaylı olarak aileyi suçlayacak olursa, şiddetli suçluluk duyguları, karşı suçlamalar ve savunuculuk gibi tepkiler ortaya çıabilir. Pek çok olguda, hastanın inthar davranışının yarattığı ofke ve kırgınlık, duyulan ilginin bir belirtisi olarak ve gerçekçi bir biçimde yeniden yapilandirlabilir. Hastanin tibbi durumu düzeldikçe, yavaş yavaş "rahatlama", "söz verme", "barışma" ve "Tanrıya şükretme" dönemine girilir. Bazı aileler ise, intihar girişiminde bulunan bireye karşı öfke ve güceniklikierini sürdürebilîler.

Pek çok anne, baba ve kardeş, daha çocuğun bedensel sağlığı dūzeimeden, kendi yaşamlarını ve çocuk ile olan ilişkilerini hızla gözden geçirirler. lyi nesne ilişkisi arama, intihar girişiminden bir anlam çıkartma, duydukfarı acı ve suçluluğu dengelemek için olumilu tutumiarını anımsama gibi dönemierin oluşturduğu bir tür muhasebe yaptir. 
Başka yakınların varığı ve aile bireyieri arasındaki paylaşımın desteklenmesi duyulan keder ilte başetmeyi kolaylaştırır. Bu süreç, "girışimin psikolojik otopsisi" gibidir. Bunun sağlıklı yanı, herkesin başbaşa verip çocuğun inthar davranışını anlamaya ve gelecekte onun yaşamına mal olabilecek yeni bir girişimi önlemeye çalışma şansının tanınmasıdırr.Ailedo girişim sonrası yoğun kaygt, korku ve gerilim yaşanır. Bu acılı dönemden geçerken aileye yardımcı olacak bir terapist varsa, önemli terapótik kazanımlar elde edilebilir. Bu dönemde aile sistemine girmek daha kolay olur. Terapist aile ile sağlam bir terapötik ilişki kurabilirse, cok yardımeı olabilir. Deneyimlerime göre, bu dönemde pek çok aile terapötik girişime açık iken, cocuk tibbi yönden iyileştikçe aile giderek daha savunucu olabilmektedir. Terapötik amaçlar açısından, bu dönem kaçırıırsa yazık olur.

Cocuk iyileştikçe ve onu yitirme korkusu azaldıkça gelecekte bulunabileceği girişimlerin korkusu ağırlık kazanmaya başlar. Pek çok hasta intihar girişimini tekrarlayabileceðinden, terapistin bu riski açıkça țartışarak, riski azaltmak için terapótik amaçlar cerçevesinde cocuk ve aileye düşen görevleri belisiemesi gerekir.

Intihar eğilimi olan çocukların ozzellikleri farkıdır. Mesajları, gereksinimleri ye belirtileri birbirine benzemez. Tablo Il'de görüldüğgü gibi. bazıları majör depressif dönem ile veya kolay düzelmeyecek daha ciddi bir ruhsal bozukluk ile karşımıza gelebilirler. Cocuğun hastalığının ciddiyetini kabul eden aileler bile, acil servis'te bekledikleri birkaç saat içinde bir "suisidektomi" yaptlamayacağını anlamakta gũçlök çekerler. "Fazla ciddi değil..." veya "Bunu yapmak istemedi..." diye umarlar. Bu çocuğun eve döneceği umudunu korumak için olduğu kadar, uzmanların gözü ile cocuğun intihar girişiminin ciddi olmadığına inanmak gereksiniminden kaynaklanır. Aileler terapistin, gocuğun ruhsal bozukluğunun özellikleri, tedavisi ve prognozuna iliş̧in bilgisini paylaşacaği bir görüşmeden çok yararlanırlar. Dikkatlerini kendine zarar verme davranışının kaynaklarına yöneltebilirler. Bu sürecin gözardı edilmesi, ailenin intihar girişiminin ciddlyetini yadsımasına yol açabilir.

Hastanın intihar etme olasıı̆ı̆ının sürmesi, aile içi gerginliğin de yüksek düzeyde sürmesine neden olur. Buna aile bireylerinin bu konudaki sorumluluklarının ağırığı ve çocuklarını yaşamda tutabilme becerilerinin kısıtlılığı yol açar. Aile bireyleri bu gerlime farklı tepkiler verirler. Ailede ilgisizlikten aşır kaygıya uzanan bir yelpaze içinde yere alan tepkiler gözlenebilir. Tutumlar da buna uygun olarak çaresizlik ve güçsuuzlükten, kurtarıcı veya Tanrı rolünün benimsenmesine kadar değişebilir. Intihar girişiminin ózellikleri ve ciddiyeti bütün bu duygu ve davranı̧̧ biçimlerini yőnlendiririr. Girişim ne denli ciddi ve örseleyici ise verilen tepkiler de o denli şiddetlidir. Öneğin, raslantı.ile eve gittiğinde 16 yaşındaki kızını yarı koma durumunda butan ve onu sirtında, aşağı taşıyarak hastaneye yetiştiren bir anne, kızı iylleştikten sonta geçici olarak çalışmayı bırakmıştı. Kı żın!n intihar davranışını yineleyeceğnii ve kendisinin haberi olmayabileceği dūşüncesine katlanamıyordu.

lyileşme süreci bir bakıma, önemll bir nesne ilişkisl yitirdiğinde yaşanan sürece benzer. Bir süre, yineleyen korkulu rũyalar görülebilir. Bir baba, kızını evlerinin ön bahçesinde olü bulduğu bir rüyayı tekrar tekrar görüyordu. Kızı eve dönmediği bir gecenin sabahında, orada bilincini yitirmiş biçimde bulunmuştu. Bu baba, iyileştikten aylarca sonra bile kızını bağışlayamadı.

Onarma dönemi boyunca pek çok aile bireyi çocuğa yakınlık ve acıma duyabilir. Bu dusggular verimli ve terapótik bir iletişimi başiatabilir. Cocuğun ruhsal durumunu anlama çabası, olumlu bir değişimin başlangıcı olabilir Onarma ve barışma sürecinde, aşırıya kaçılmamasına dikkat edilmelidir. Bazı aileler sını koymaktan vazgeçip. "teslim olarak" hastayı "intihar silahının" güclenmesine ve "vazgeçilmez" duruma gelmesine yol acacak denti şımartabilinter.

Ailenin diğer çocukları, intihar eğilimi olan çocuğa ôzenebilirler. 10 yaşındaki bir cocuk, "bize de kardeşime davrandıkları gibi davranmaları için hepimiz ilaç yutmalıyız" demişti. Bazı çocukiar ailenin ilgisi ve bakımını dengelemek için kendilerine zarar verecek denli ileri gidebilirler. Aile, ozellikle anne ve baba "köklü çözüm bulmak" ile uğraşırken, diğer çocukların bakımı ve gereksinimleri özardı edebilir.

Sağlıklt bir iyileşme sürecinden geçen ailelerde vardır. Bununla birlikte, dengenin sağlıksız biçimde değişmesi bireylerin ve bir bütün olarak ailenin gelişim sürecinde sorunlar 
yaratabilir. Terapist, olumlu gelişmenin sürmesi ve intihar riskinin en aza indirgenmesi için bu gelişim sürecini yakından izlemelidir.

Bazı aileler terapiyi zamanından önce sonlandirabilirler. Bu aileler terapiye geri döndüklerinde sağlıksız bir iyileşme süreci betimierler, intihar davranışının yarattığı korku, kaygı gibi duygular ve açığa çıkan enerii, terapötik danışmanlık aracılığı ile olumlu değiş̧im için kullantlabilir. Pek çok aile intihar girişiminin ardından terapistin desteğl olmaksızın yalnızca kendi kaynaklarinı kullanarak olumlu gelişme gösterebilir. Ne yazık ki bu konudaki bilgimiz, hangi ailelerin bunu başarma şansının yüksek olduğunu yordamamıza yetmemektedir.

Ailenin, intihar davranışının etkisinden tümüyle kurtulmasını beklemek gerçekçi olmaz. Pek çok aile terapistin desteği ile yaşamłarını sürdürebilecekleri bir kısmı iylleşme dönemine ulaşırlar. Bir yandan da intihar girişiminden arta kalanlar lie uğraşıp uğradıkları zararı kapatmaya ve kazanımlarını korumaya çalışırlar.

Bazı etkenler iyileşme sürecini yavaşlatır. Ailede ciddi işlev bozukluğu, ailenin kriz ile başetme becerilerinin kısıtlilığ! gelecekte intihar davranışının yinelenmesi tehdidinin sürmesi, tedaviye dirençli ruhsal hastalığı olan veya işbirliği yapmayan bir çocuk, bu süreçte önemli sorunlar yaratabilit.

Onarma döneminde intihar davranışının yaptığı etki yalnızca intihar girişiminde bulunan bireyin kendisi tarafından değgit, allenin diğer bireyleri tarafından da kullanilabilir. Bir anne, 17 yaşındaki kızının intihar etme riskini, evden uzaklaşan kocasını geri getirmek için kullanmış; bu da babanın kızına karşı duyduğu olumsuz duyguları arttırmıştı.

Tedavinin başlarında pek çok aile üyesinin gerçekte karmaşık olan intihar davranışını açıklamak için "basit yanıtlar" aradıkları görülür. Bu basite indirgeme çabasi bu konudaki bilgisizlikten kaynaklanır. Aslında ailenin kơkularını azaltmayı amaçlayan uyuma yönelik bir tutumdur. Her insan sorunlarının basit ve kolayca başedilebliir olmasını ister. Terapist, ailenin dikkatini yavaş yavaş çok etmenli etyolojiye ve sistem içi bağlantilara çekmeye çaıışmalıdır.
Araştırmada ailelerin hevesli oluşları ve yoğun çaba göstermeleri çok yararil olmuştur. Bu çalışmaya alınan allelerin hemen hepsi, intihar eğilimi olan genci anlamak ve ona yardım etmek için içtenlikle uğraştılar. Yoğunlaştırıimış, bütünleyici aile yaklaşımı ailenin iyjleşme sürecini hızlandımakta oldukça etkin oldu.

Intihar girişiminin hemen ardından gelen akut kriz döneminde, terapl kontratına ailede saptanan işlevsel bozuklukların da katıması cok önemlidir. İntihar eğilimi olan cocuk ve ergenlerin aileleri ile yapılan destekleyici ve terapotik çalışma ve hastanın nöroendokrin, ruhsal ve çevresel sistemlerine yönelik diğer terapötik yaklaşımlar bưtünleyici olmaktadır.

\section{KAYNAKLAR}

Ackerly, W,C.(1967) Latency-age children who threaten or attempt to kill themselves. I Am Acad Child Psychiatry 6:242-261,

Aleksondrowicz, M,K. (1975)The biological strangers :An attempted suicide of $71 / 2$ year-old girl. Bull Menninger Clin 39:163-176,

Asberg, $M$. Nordström $P$, Traskman-Bendez $L$ : (1986) Biological factors in suicide, in Roy $A$ (ed): Suicide, Baltimore, Williams \& Wikins, , pp 47-71

Bakwin $1,1,:(1957)$ Suicide in children and adolescents. J Pediatr 50:749-769,

Barraclough D:(1986) Sex ratio of juvenile suicide J. Am. Acad. Child Adolesc. Psychiatry 26:434-435,

Barter J,T,1968 Swaback DO.Todd D: Adolescent suicide attempts: $A$ tollow-up of hospitalized patients. Am. J. of Psychiatry 19:523-527,

Bender, L, Schilder P, (1937) Suicidal preoccupations and attempts in children. Am. J. Orthopsychiatry. 7:223-235,

Bergstand C,G, Otto, U. (1962) .Suicidal attempls in adolescence and childhood. Acta. Pediatr $51: 17-26$, 
short-term therapy: An approach in child psychiatric clinic. J. Am. Acad. Child Psychiatry 9:595-606,

Brent D,A, Kalas, R, Edelbrock G. ot.al. (1986) Psychopathology and its relationship to suicidal idention in the childhood and adolescent. J. Am. Acad. Child Psychiatry 25:666-671

Brent D,A. (1987) Correlates of the medical lethality of suicide attempts in children and adolescents J. Am. Acad. Child Adolesc Psychiatry. 26:87-89,

Carlson G,A, ((1983) Depression and suicidal behavior in children and adolescents. In Cantwell DP. Carlson GA (eds):Affective Disorders in childhood and Adolescence:An Update. Now York. Spectrum. pp 335-352

Carlson G,A, Asarow J,R, Orbach 1.(1987): Developmental aspects of suicidal behavior in children. J. Am. Acad. Child Adolesc. Psychiatry 26: 189-192

Chicfetz P,N, Posener J,A, LeHaye A, et.al. (1987) An epidemiologic study of adolescent suicide. Can. J. Psychiatry 32:656-659

Cohen-Sandiar A, Berman, A. (1982) A follow-up study of hospitalized suicidal children. J. Am. Acad. Child Adolesc. Psychiatry 21:414-416

Corder B, F, Shorr, W, Corder, R,F. (1974) A Situdy of social and psychological characteristic of adolescent suicide attemtpts in urban disadvantaged area.Adolescence 9:1-6,

Crumley, F,E.(1982): The adolescence suicide attempl: A cardinal symptom of a serious psychiatric disorder. Am. J. Psychother 36:158-165.

Deykin, E, Y, Perlew, R., McNamarra, J. (1985) Non-fatal suicidal and life-threatening behavior among 13- to 17-year-old adolescents seeking emergency medical care. Am J Public Health 75:90-92.

Durkeim, E. (1897) Le Suicide, Translated by JA Spaulding, G Simpson, New York, Free Press,

Eisenberg, L. (1986) Adolescent suicide: On taking arms against a sea of troubles. Pediatrics 66:315-320.

Emery, P.E. (1983) Adolescent depression and suicide. Adolescence 18:245-258.

Finch, S,M. Pozansk, E,O. (1971) ,Adolescent Suicide. Springfield, Minois, Charles C Thomas.

French AP, Steward M: Family dynamics, childhood depressin and attempted suicide in a -7-year-old boy: A case study Suicide 5:29-37,1975

Freud, $S$, (1917): Mourning and melancolia. In Complete Psychological Works.Standard Ed. Vol 14. London, Hogarth Press, 1955

Garfinkel, B,D. Forese, A..; Hood, J. (1982) Suicide attempts in children and adolescents. Am. J. Psychiatry, 139:1257-1261

Garfinkel, B.D.; Goolombek, H. (1983) Suicidal behaviot in adolescence. In Golombek $\mathrm{H}$. Garfinkel BD (eds): The Adolescent and Mood Disturbance. Now York International Universities Press: pp 189-217

Glaser, K. (1978) Attempted suicide in children and adolescents: Psychodynamics. Am. J. Psychother, 32: 225-227

Glaser K, (1981) Psychopathic patterns in depressed adolescents,. Am. J. Psychother, 35:368-382

Green $A_{1} H_{.}$(1978) Self-destructive behavior in battered children Am. J. Psychother, 135:579-582

Haim, A. (1974) Adolescent Suicide. New York, International Universities Press.

Haider, 1(1968) Suicidal attempts in children and adolescents. Br. J. Psychiatry 114:1133-1134

Hawton, $K$. (1986) Suicide in adolescents. In Roy $A(e d)$ : Suicide, Baltimore, Williams \& Wilkins. pp 135-150

Hollinger P,C.(1978) Adolescent sulcide :An epidemiologic study of recent trends, Am. J. Psychiatry. 135: 754-756 
and Adolescents, New York. SP Medical and Scientific Books

inamdar, S,C, Lewis D,O, Sicmopouios, G, et.al. (1982) Violent and suicidal behavior in psychotic adolescents. Am. J. Psychiatry 139.932-935

Joffe, R.T. Offord D,R. (1983) Suicidal behavior in childhood. Can. J. Psychiatry, 28:57-63

Kazdin, A,E, French N,II, Unis A,S. ot.al.(1983) Hopelessness, depression and suicidal intent among psychiatrical disturbed in-patient children. J. Consul. Clin. Psychoology 51:504-510

Kerfoot, M. (1980) The family context of adolescent suicidal behavior. I Adolesc. 3:335-346.

Klerman, G,L. (1986): Suicide and Depression Among Adolescents and Young Adults.Washington: American Psychiatric Press.

Kosky, R. (1982) Suicide and attempted suicide among Australian children. Med.J.Aust. 124-126,

Lawler, R,H, Nakleiny, W, Wright $N$. (1963) Suicidal attempts in children. Can. Med. Assoc. J. $89: 751-754$

Lesse, S. (1975) The range of theories in the treatment of severely depressed suicidal patients. Am. J. Psychother. 29:308-326.

Luklonowlez, N.(1968) Attempted suicide in children. Acta. Psychiatr. Scand 44:415-435.

Mattsson A, Seese L, R, Hawkins J, W. (1969) Suicidal behavior as a child psychiatric emergency. Arch. Gen. Psychiatry, 20:100-109

McClure G, Gould M,S, (1984) Recent trends in suicide among the young. Br. J. Psychiatry 144:134-138.

Mclntire, M.S.; Angle, C. R. (1973) Psychoological "biopsy" in self-poisoning of children and adolescents. Am. J. Disord. Child 126:42-46.

McKenry, P.C.; Tishler C.L.; Kelley, C. (1982) Adolescent suicide: A Comparison of attempters and nonattemplers in emergency room population. Clin. Pediatr. 21: 266-270.

Meares, A.; Kraiuhin, C.; Benfield, J (1983) Adolescent suicide, Aust. Fam. Phys. 12:614-616.
Williams \& Wikins.

Menninger, J. (1933) Psychoanalytical aspects of suicide. Int. J. Psychoanal. 14: 376-390.

Menninger, K,A. (1938) Man Against Himself. New York: Harcourt, Brace.

Minde, K.K. (1986) Suicide in children and adolescents. Ann. ACFSC. 19:29-33.

Morrison, G.C.; Collier, I.G. (1969) Family treatment approaches to suicidal children and adolescents. J. Am. Acad. Child Adolesc. Psychiatry. 8:140-153

Motto, J. A. (1985) Treatment concerns in preventing youth suicide. In Peck ML, Farberow, NL. Litman RE (Eds). Youth suicide New York, Springer Publishing Company, pp 91-111.

Myers, K.M.; Burke, P.; McCauley, E. (1985) Suicidal behavior by hospitalized preadolescent children on a psychiatric unit. J. Am. Acad. Child. Psychiatry 24: 474-480.

Orbach, 1. Rosenheim, E, Hary, E.(1987)Some aspects of cogtive functioning in suicidal children. J. Am. Acad. Child. Adolesc. Psychiatry. 26. 181-185.

Otto, W. (1964) Changes in behavior of children and adolescents preceding suicidal attempts. Act Psychiatr. Scand. 40: 386-399.

Otto, $U$. (1972) Suicidal acts by children and adolescents : A follow-up study. Acta. Psychiatr. Scand. 233(Supp): 5-123.

Paulson, M.J.; Stone, D.; Sposto, A. (1978) Suicide potential and behavior in children ages 4-12. Suicide Life. Threat. Behav. 8:225-242.

Peck, M.L.; (1980) Recent Trends in Suicide Among Young People. Los Angeles, Institute for Studies of Destructive Behaviors

Peck, M.L. (1985) Crisis intervention treatment with chronically and acutely suicidal adolescents. In Peck ML.Farberow NL. Litman RE (Eds): Youth Suicide. New York, Springer Publishing Company, pp 112-122

Peck, M.L.; Farberow N.L.; Litman, A.E. (1985) Youth Suicide, New York, Springer Publishing Company. 
Pfoffer, C., Conte, H. R.; Plutchik. et.al. (1979) Suicidal behavior in latency age children. J. Am. Acad. Child. Psychiatry, 18:679-692.

Preffer, C, R. (1981) Suicidal behavior of children: A review implicalions for research and practise. Am. J. Psychiatry 138:154-159.

Preffer, A.C.(1981) The family system of suicidal children. Am. J. Psychother. 35:330-341.

Preffer,C.R.; Phutchik, R.; Mizruchi, M.S. (1983) Suicidal and assaulteve behavior in children: Classification, measurement, and interrelations. Am. J. Psychiatry. 140: 154-157.

Pretfer, C.A.; Zuckerman, S.; Plutchik, R. et.al. (1984) Suicidal behavior in normal school children: $A$ comparisons with child psychiatric inpatients, $J$. Am. Acad. Child. Psyciatry. 23:416-423

Preffer, C. A. (1986) : The Suicidal Child, New York: Guifford Press

Preffer, C.R.; Newcorn, J.; Kaplan, G. et.al. (1988) Sulcidal behavior in adolescent psychiatric inpatients. J. Am. Acad. Child. Adoles. Psychiatry 27:357-361.

Feport of the National Task Force (1987) Sulcide in Canada. Sponsored by the Mental Health Division, Health Services and Promotion Branch, Health and Welfare Canada.

Robbins, D. R.; Alessi, N.E. (1985): Deepressive symptoms and suicidal behavior in adolescents. Am. J. Psychiatry, 142: 588-592

Rosenberg, P. H; Latimer, R.(1966) Suicide aftempts by children. Ment Hygiene. 50:354-359.

Roy, A. (1986) Suicide. Baftimore, Williams \& Wikins.

Sabbath, J.C. (1969) The suicidal adolescent: The expendable child. J. Am. Acad. Child. Psychiatry 8:272-289.

Sainsbury, P. (1986) The epidemiology of suicide. In Roy A (ed): Suicide. Baltimore, Williams \& Wikins, pp 17-40.

Schecter, M. D. (1957) The recognition and treatment of suicide in children. In Schneidman E, Farberow $N$ (eds): New York, Blakiston, pp 131-143.
Schneer, I,I,I ; Peristein, A.; Brozovsky, M. (1975) Hospltalized suicidal adolescents: Two generations. J. Am. Acad. Child. Psychiatry. 14: 268-280

Schrut, A.(1964) Suicidal adolescents and children. JAMA 188:1102-1107.

Schaffer, D. (1974): Suicide in childhood and early adolescence. J. Child. Psychol. Psychiatry. 15:275-291.

Shaffer, D.; Fisher, P. (1981)The epidemiology of suicide in children and young adolescenfs. J. Am. Acad. Child. Psychiatry. 20:545-565.

Shaifer, D. (1986) Developmental factors in child and adolescent suicide. In Putter, M, Izard, $c$, Aead P. (eds): Depression in Young People, New York, Guifford Press. pp 383-396.

Shaw, C.R.; Schelkum, R.F. (1963) Suicidal behavior in children Psychiatry. 28:157-168.

Stanley, E.J.; Barter, J.T. (1970) Adolescent suicidal behavior. Am. J. Orthopsychiatry. 40:87-96.

Sudak, I.S.; Ford, A.B.; Rushtort, N.B. (1984) Suicide in the Young. Boston: Yohn Wright.

Turgay, A. (1982) Psychiatric emergencies in chiloren. Psychiatr J. Unic. Ottawa. 7:254-260.

Veelvez, C.N.; Cohen, P. (1986) Suicidal behavior and ideation in a comminity sample of children: Maternal and youth reports. J. Am. Acad. Child. Adolesc. Psychiatry. 27: 349-356.

Ward, J.A.;Fox, J. (1977)Suicide epidemic on an Indian reserve. Can. Psychiatr. Assoc. J. 22: $423-426$.

Winn, D.; Halls, R. (1966) Observations of children who theaten to kill themselves. Can. Psychiatry. Assoc J. 11:283-294.

Ziboorg, G.(1937) Considerations on suicide, with particular reference to that of the young. Am. J. Orthopsychiatry. 7: 15-31. 